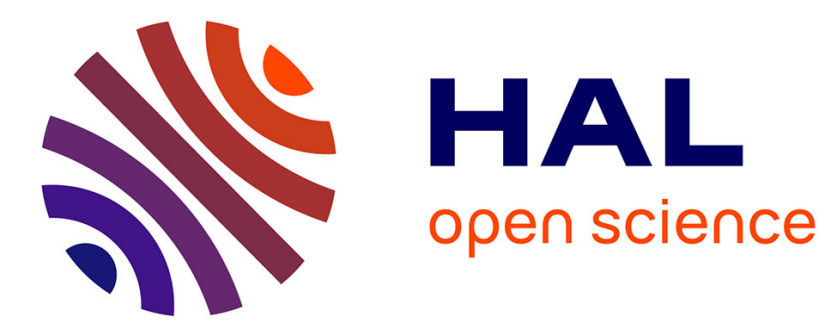

\title{
Redistribution of interstitial atoms and ageing of Fe-N $\alpha$ martensite
}

\author{
J. Foct, C. Cordier-Robert
}

\section{To cite this version:}

J. Foct, C. Cordier-Robert. Redistribution of interstitial atoms and ageing of Fe-N $\alpha$ martensite. Journal de Physique IV Proceedings, 1993, 03 (C7), pp.C7-127-C7-130. 10.1051/jp4:1993719 . jpa00251822

\section{HAL Id: jpa-00251822 \\ https://hal.science/jpa-00251822}

Submitted on 1 Jan 1993

HAL is a multi-disciplinary open access archive for the deposit and dissemination of scientific research documents, whether they are published or not. The documents may come from teaching and research institutions in France or abroad, or from public or private research centers.
L'archive ouverte pluridisciplinaire HAL, est destinée au dépôt et à la diffusion de documents scientifiques de niveau recherche, publiés ou non, émanant des établissements d'enseignement et de recherche français ou étrangers, des laboratoires publics ou privés. 


\title{
Redistribution of interstitial atoms and ageing of Fe- $\mathbf{N} \alpha^{\prime}$ martensite
}

\author{
J. FOCT and C. CORDIER-ROBERT
}

Laboratoire de Métallurgie Physique, URA CNRS 234, Université Lille I, Bâtiment C6, 59655 Villeneuve d'Ascq, France

\begin{abstract}
Different experimental measurements show that transformations of martensite occur from very low temperature, often below $77 \mathrm{~K}$. In order to understand the redistribution of interstitial atoms which is studied by Mössbauer spectrosopy near room temperature the previous low temperature changes are briefly discussed. The Mössbauer data related to cubic $\gamma, \gamma^{\prime}, \alpha^{\prime}$ and $\alpha^{\prime \prime} \mathrm{Fe}-\mathrm{N}$ alloys are presented. It is shown that the interstitial atom distribution and redistribution of interstitial atoms is partially inherited from austenite and that $\gamma^{\prime} \mathrm{Fe}_{4} \mathrm{~N}$ nuclei corresponds in $\gamma$ and $\alpha^{\prime}$ to $\mathrm{N}$ Fe-N chains oriented along $<001>$ in $\gamma$ and along $<110\rangle$ in $\alpha$.
\end{abstract}

\section{I - LOW TEMPERATURE TRANSFORMATIONS OF Fe-N $\alpha$ ' MARTENSITE}

The internal friction peaks which are observed near 100, 200 and $270 \mathrm{~K}$ during the first heating of a virgin $\alpha$ ' martensite obtained under a $\mathrm{M}_{\mathrm{S}}$ temperature low enough to prevent any "auto-ageing" correspond to hysteretic irreversible phenomena [1-3]. In order to understand these changes which occur in $\alpha^{\prime}+\gamma$ specimen complementary measurements have been done by dilatometry [4], $X$ ray diffractometry [5], Mössbauer spectrometry [6-9], resistivity [10]. Although Mössbauer spectra do not show clear evidences of changes below $270 \mathrm{~K}$ an unambiguous variation of the tetragonality c/a was measured (table I).

\begin{tabular}{|l|c|c|c|c|c|}
\hline & Fe-33.5Ni & Fe-30Ni-0.37C & Fe-25Ni-0.7C & Fe-2.39N & Fe-3Mn-1.6C \\
\hline$\Delta c / a$ & -0.008 & -0.015 & -0.01 & -0.02 & +0.008 \\
\hline
\end{tabular}

Tableau I: Change of tetragonality after heating from $4 \mathrm{~K}$ to about $250 \mathrm{~K}$, from experimental results obtained by K. ULLAKO [10]

The main hypothesis which have been proposed to interprete these variations are:

A - Redistribution of interstitials between $\mathrm{O}_{x}, \mathrm{O}_{y}$ and $\mathrm{O}_{z}$ sites [11],

$B$ - Redistribution of interstitials between tetragonal and octahedral sites [12],

C - Interaction between defects - Interfaces boundaries $\alpha / \gamma$-Dislocations - $\mathrm{C}$ and $\mathrm{N}$ atoms...

Hypothesis $\mathrm{B}$ has been rejected and no unambiguous evidence of the $\mathrm{A}$ processus was obtained when temperature is below $200 \mathrm{~K}$ [13] therefore $\mathrm{C}$ is the main source of low temperature phenomena. Schematically these very low temperature changes can be considered as relaxation-type processes i.e. by which the free energy of the system decreases by reorganization of the defects which relaxes stresses and strains. 
Although low temperature changes of c/a are observed even when virgin martensite does not contain interstitial atoms, they appear to be mainly due to interstitial defect interactions. According to these views it can be proposed that in $\mathrm{FeN}_{x}$ martensite the density of $\mathrm{N}$ atoms in $\mathrm{O}_{\mathbf{x}}, \mathrm{O}_{\mathbf{y}}$ and $\mathrm{O}_{z}$, and near defects are $\mathrm{X}_{\mathrm{X}}, \mathrm{X}_{\mathrm{y}}$ and $\mathrm{X}_{\mathrm{Z}}$ sites and $\mathrm{X}_{\mathrm{D}}\left(\mathrm{X}=\mathrm{X}_{\mathrm{X}}+\mathrm{X}_{\mathrm{Y}}+\mathrm{X}_{\mathrm{Z}}+\mathrm{X}_{\mathrm{D}}\right)$.

According to the fact that the interplanar distance measured by $\mathrm{X}$ ray diffraction corresponds to an integration of the mean static displacements:

$$
\begin{aligned}
& a=a_{0}\left\{1+\alpha\left[X_{x}+X_{y}\right] / 2-\beta\left[X_{z}+\left(X_{x}+X_{y}\right) / 2\right]+\varepsilon X_{D}\right\} \\
& c=c_{o}\left\{1+\alpha X_{z}-\beta\left[X_{X}+X_{y}\right]+\varepsilon X_{D}\right\}
\end{aligned}
$$

which lead to $c / a=1+(\alpha+\beta)\left[X_{z}-\left(X_{X}+X_{y}\right) / 2\right]$ and $\Delta V / V=(\alpha-2 \beta)\left[X-X_{D}\right]+3 \varepsilon X_{D}$. These equations show that the tetragonality $c /$ a as well as $\Delta V / V$ may change if $X_{D}$ varies.

It is clear that $\mathrm{X}_{\mathrm{D}}$ leads to minor changes of the Mössbauer spectra but possibly to important changes of c/a and $\Delta \mathrm{L} / \mathrm{L}$, both values which should be discussed in parallel. It should be emphasized that all the low temperature relaxation - type transformations of martensite do not suppose any change in the Zener ordering. However in the vicinity of substitutional S atoms, such as $\mathrm{Mn}$ or $\mathrm{Cr}$, short range order which is induced by the S-N interaction is likely to delay the Zener ordering, and could explain the important increase of tetragonality in $\mathrm{Mn}$ alloyed martensites.

Once the relaxation of the martensite is accomplished on can estimate $\mathrm{X}_{\mathrm{D}} \approx 0.1 \mathrm{X}$ and $\mathrm{X}_{\mathrm{Z}} \approx \mathrm{X}-\mathrm{X}_{\mathrm{D}}=0.9 \mathrm{X}$. After relaxation of the $\alpha^{\prime}$ lattice because $X_{D} \neq 0$, it seems very probable that the values of the local deformation based on the variation of $a$ and $c$ versus $X$ are underestimated. When the relaxation stage is achieving, ageing of martensite resulting from a redistribution of interstitials on $\mathrm{O}_{z}$ sites, which preserves Zener order, may occur (figure 1).

\section{II - MÖSSBAUER RESULTS AND DISCUSSION}

Since early studies of ageing of Fe-C and Fe-N martensites, it was clear that Mössbauer spectra led to characterize iron environments in the different phases and that the main source of identification of the hyperfine parameters and therefore of the Mössbauer peaks is the number of interstitial nearest neighbours. Let us identify environments by the number of first nitrogen nearest neighbours $\mathrm{O}, \mathrm{I}, \mathrm{II}$ [14] in the different $\mathrm{FeN}_{\mathrm{x}}$ phases $\gamma, \gamma^{\prime}, \alpha^{\prime}, \alpha^{\prime \prime}: \mathrm{O}^{\gamma}, \mathrm{O}^{\gamma^{\prime}}, \mathrm{O}^{\alpha^{\prime}}, \mathrm{O}^{\alpha^{\prime \prime}}-\mathrm{I}^{\gamma}, \mathrm{I}^{\gamma}, \mathrm{I}^{\alpha^{\prime}}, \mathrm{I}^{\alpha^{\prime \prime}}-\mathrm{II}^{\gamma}, \mathrm{I} \gamma^{\gamma}, \mathrm{II}^{\alpha^{\prime}}, \mathrm{II}^{\alpha^{\prime \prime}}$.

Figure 2 shows the peaks corresponding to these environments during ageing of $\alpha^{\prime}$. II ${ }^{\gamma}$ has been clearly identified in $\mathrm{FeN}_{\mathrm{x}}$ austenite since twenty years [15]. This II $\gamma$ environment essentially corresponds to $\mathrm{N}$ $\mathrm{Fe}-\mathrm{N}<100>$ chains which are isomorphous to those observed in $\gamma$ and which correspond to $\mathrm{II}^{\gamma}$. These environments act as nuclei for $\gamma$ precipitation during ageing of austenite [14].

The spectrum of $\gamma^{\prime}$ is also unambiguous, the splitting of $\mathrm{II}^{\gamma}$ into two $\Pi_{\|} \gamma^{\gamma}$ and $\Pi_{\perp} \gamma^{\prime}$ environments corresponds to the two possible angles formed by the direction of easy magnetization with the electric field gradient axis [16]. It must be mentionned that when nitrogen content $X$ of $\gamma / F e N_{x}$ is slightly lower than 0.25 an environment $\gamma^{\gamma}$ has been identified and corresponds to iron atoms of type II $^{\gamma}$ for which one nitrogen nearest neighbour is replaced by a vacancy.

An unambiguous interpretation of $\alpha^{\prime \prime}$ has been proposed [16] which shows that the splitting of $I^{\alpha \text { " into }}$ $\mathrm{I}_{\|}{ }^{\alpha "}$ and $\mathrm{I}_{\perp} \alpha^{\prime \prime}$ corresponds to sites at the corner of the irregular octahedron and is consistent with the expected abundances ratio: 2 . The very high value of the hyperfine magnetic field corresponding to $\mathrm{O}^{\alpha \text { " }}$ higher than 40T is the reason for the high saturation magnetization of $\mathrm{Fe}_{16} \mathrm{~N}_{2} \alpha$ " and corresponds to the expansion of the $\mathrm{Fe}-\mathrm{Fe}$ distances when $\mathrm{N}$ atoms are further from iron atoms than $\mathrm{a}_{\alpha}, \sqrt{2} / 2$.

In virgin $\alpha^{\prime}$ martensite $\mathrm{O}^{\alpha^{\prime}}, \mathrm{I}_{\|} \alpha^{\prime}$ and $\mathrm{I}_{\perp} \alpha^{\prime}$ isomorphous to $\mathrm{O}^{\alpha}, \mathrm{I}_{\|}{ }^{\prime \prime}$ and $\mathrm{I}_{\perp} \alpha^{\prime \prime}$ are clearly identified. An important site $O^{\prime} \alpha^{\prime}$ is also visible on the spectra. Up to now and curiously, no clear interpretation of $O^{\prime} \alpha^{\prime}$ 
was proposed. In austenite $\mathrm{N}-\mathrm{N}$ interactions are highly repulsive and therefore the $\mathrm{N}$ distribution forms $\mathrm{N}-\mathrm{N}<110>$ doublet building the frame of the $\gamma$ "-like structure likely to lead to $\alpha$ " by a Bain tranformation (figure 3). If the nitrogen distribution on the possible sites of $\gamma^{\prime \prime}$, i.e. $\alpha$ ", is nearly random, the density of sites $O$ having i $N$ third nearest neighbours $(0 \leq \mathrm{i} \leq 4)$ is:

$\mathrm{PO}_{\mathrm{i}} \alpha^{\prime}=\left(1-6 \mathrm{x}^{\prime}\right) \mathrm{C}_{4}{ }^{\mathrm{i}}\left(8 \mathrm{x}^{\prime}\right)^{\mathrm{i}}\left(1-8 \mathrm{x}^{\prime}\right)^{4-i}$, where $\mathrm{x}^{\prime}$ is the isolated nitrogen interstitial concentration i.e. $x$ diminished by interstitials forming $\mathrm{N}-\mathrm{Fe}-\mathrm{N}$ chains. Measurements of peaks area show that $\mathrm{O}^{\prime} \alpha^{\prime}$ corresponds to environments $\mathrm{O}_{i}^{\alpha^{\prime}}$ with $i \geq 3$.

An other environment is detected in $\alpha^{\prime}: \Pi^{\alpha^{\prime}}$ of which the hyperfine field is near that of $\mathrm{I}^{\prime}$. This led other authors to conclude to the presence of $\gamma^{\prime}$ in $\alpha^{\prime}$ [17]. In fact this corresponds to $\gamma^{\prime}$ embryos inherited from the II $\gamma^{\gamma}$ environment. These $\gamma^{\prime}$ embryos are formed by $\mathrm{N}-\mathrm{Fe}-\mathrm{N}\langle 110\rangle_{\alpha}$, chains according to the evolution of site abundances during ageing (figure 4) [18].

\section{III - CONCLUSION}

The following sequence for the appearance of sites may be proposed:

- (1) Martensite transformation:

$\gamma\left\{\mathrm{O}^{\gamma}, \mathrm{I}^{\gamma}, \mathrm{II}^{\gamma}\right\} \rightarrow \gamma_{\mathrm{R}}+\alpha^{\prime}{ }_{\mathrm{V}}\left\{\mathrm{O}^{\alpha^{\prime}}, \mathrm{O}^{\prime} \alpha^{\prime}, \mathrm{I}_{\|}^{\alpha^{\prime}}, \mathrm{I}_{\perp} \alpha^{\prime}, \mathrm{II}^{\alpha^{\prime}}\right\}$, with a tetragonality of martensite (c/a) $\mathrm{O}$

- (2) Relaxation stage:

$\alpha^{\prime}{ }_{\mathrm{V}}\left\{\mathrm{O}^{\alpha^{\prime}}, \mathrm{O}^{\prime \alpha^{\prime}}, \mathrm{I}_{\|}^{\alpha^{\prime}}, \mathrm{I}_{\perp}^{\alpha^{\prime}}, \mathrm{II}^{\alpha^{\prime}}\right\}->\alpha_{\mathrm{R}}^{\prime}\left\{\mathrm{O}^{\alpha^{\prime}}, \mathrm{O}^{\prime \alpha^{\prime}}, \mathrm{I}_{\|}^{\alpha^{\prime}}, \mathrm{I}_{\perp}^{\alpha^{\prime}}, \mathrm{I}_{\mathrm{D}}^{\alpha^{\prime}}, \mathrm{I}^{\alpha^{\prime}}, \mathrm{II}_{\mathrm{D}}{ }^{\alpha^{\prime}}\right\}$, with $(\mathrm{c} / \mathrm{a})_{\mathrm{R}} \neq(\mathrm{c} / \mathrm{a})_{\mathrm{O}}$.

- (3) Ageing of FeN ${ }_{x}$ martensite:

Spinodal like decomposition of $\alpha_{\mathrm{R}}^{\prime}, \alpha_{\mathrm{R}}^{\prime}>\alpha^{\prime \prime}+\alpha_{\mathrm{A}}$

$\left.\alpha^{\prime}{ }_{\mathrm{R}}\left\{\mathrm{O}^{\alpha^{\prime}}, \mathrm{O}^{\prime \alpha^{\prime}}, \mathrm{I}_{\|} \boldsymbol{\alpha}^{\prime}, \mathrm{I}_{\perp}{ }^{\prime}, \mathrm{I}_{\mathrm{D}}^{\alpha^{\prime}}, \mathrm{I}^{\alpha^{\prime}}, \mathrm{II}_{\mathrm{D}}{ }^{\prime}\right\}\right) \alpha_{\mathrm{A}}\left\{\mathrm{O}^{\alpha}, \mathrm{I}^{\alpha}\right\}+\alpha^{\prime \prime}\left(\mathrm{O}^{\alpha^{\prime \prime}}, \mathrm{I}_{\|} \alpha^{\prime \prime}, \mathrm{I}_{\perp} \alpha^{\prime \prime}\right\}$

with $<c / a>_{A} \approx f_{\alpha^{\prime \prime}}(c / a)_{\alpha "}+\left(1-f_{\alpha^{\prime \prime}}\right)$, where $f_{\alpha "}$ is the volume fraction of $\alpha^{\prime \prime}$.

- (4) Tempering:

$\alpha_{\mathrm{A}}\left\{\mathrm{O}^{\alpha}, \mathrm{II}^{\alpha}\right\}+\alpha^{\prime \prime}\left\{\mathrm{O}^{\alpha^{\prime \prime}}, \mathrm{I}_{\|} \alpha^{\prime \prime}, \mathrm{I}_{\perp} \alpha^{\prime \prime}\right\}-\alpha_{\mathrm{T}}+\gamma^{\prime}\left\{\mathrm{O}^{\gamma \prime}, \mathrm{I}^{\prime \prime}, \mathrm{II}_{\|} \gamma^{\prime \prime}, \mathrm{II}_{\perp} \gamma^{\prime \prime}\right\}$ with $(\mathrm{c} / \mathrm{a})_{\mathrm{T}}=1$.

The $\mathrm{N}-\mathrm{Fe}-\mathrm{N}$ chains inherited from $\gamma$ act as nuclei for $\gamma^{\prime}$ precipitation.

\section{REFERENCES}

[1] PRIOUL C., CARRARD M., J de Physique, Colloque C5, t. 42 (1981), 1007.

[2] De A RODRIQUES C.A.V., PRIOUL C., HYSPECKA L., Metall. Trans. 15A (1984), 2193.

[3] LIU Y., Acta Metall. Mater. 41, 5 (1993), 1587-1593.

[4] LIU CHENG, STARK I., KOREVAAR B.M., MITTEMEIJER E.J., SMITH G.D.W., High

Nitrogen Steels, HNS88, J. FOCT and A. HENDRY Eds, The Institute of Metals, 453 (1989), 97.

[5] ULLAKKO K., GAVRILJK V.G., Acta Metall. Mater., 99 (1990).

[6] GRELEN, KAPLOW, Acta Metall., 15 (1967), 49.

[7] GENIN J.M.R., FLINN P.A., TMS AIME, 242 (1968), 1419.

[8] FOCT J., GENIN J.M.R., C. R. Acad. Sci., 270 (1970), 1563.

[9] GENIN J.M.R., FOCT J., Phys. Stat. Sol. (a), 17 (1973), 395.

[10] ULLAKO K., Thesis, Helsinki University of Technology, (1992).

[11] KURDJUMOV G.V., KHACHATURJAN A.G., Acta Metall., 23 (1975), 1077.

[12] LYSAK L.I., Phys. of Metals and Metallogr., 43, 3 (1977), 130.

[13] GRIDNEV V.N., GRAVRILJUK V.G., NEMOSHKALENKO V.V., POLUSHKIN Ju. A., RAZUMOV O.N., Phys, of Metals and Metallogr. 43, 3 (1977), 109.

[14] FOCT J., ROCHEGUDE P., HENDRY A., Acta Metall., 36, 3 (1988), 501.

[15] FOCT J., C. R. Acad. Sci., 276 (1983), 1159.

[16] ROCHEGUDE P., FOCT J., Phys. Stat. Sol. (a), 98 (1986), 51.

[17] GAVRILJUK V.G., NADUTOV V.M., ULLAKKO K., Scripta Metall., 25 (1991), 905.

[18] FOCT J., CORDIER-ROBERT C., ROCHEGUDE P., HENDRY A., High Nitrogen Steels, HNS88, 453 (1989), 102. 


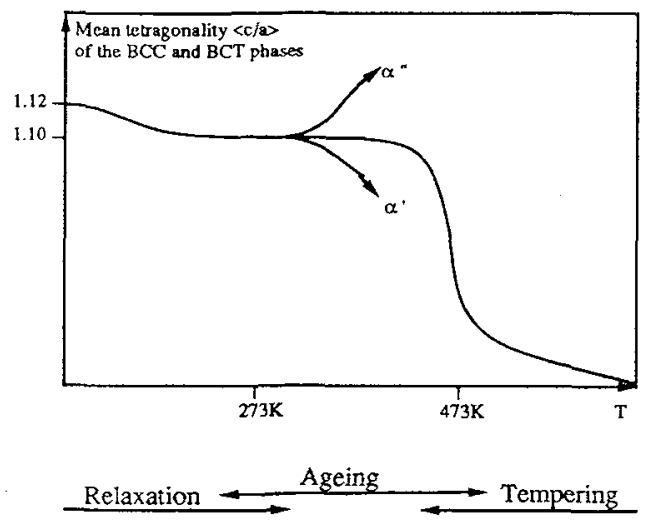

Figure 1: Evolution of the mean tetragonality $<\mathrm{c} / \mathrm{a}>$ of $\mathrm{BCC}$ and $\mathrm{BCT}$ phases vs. temperature.

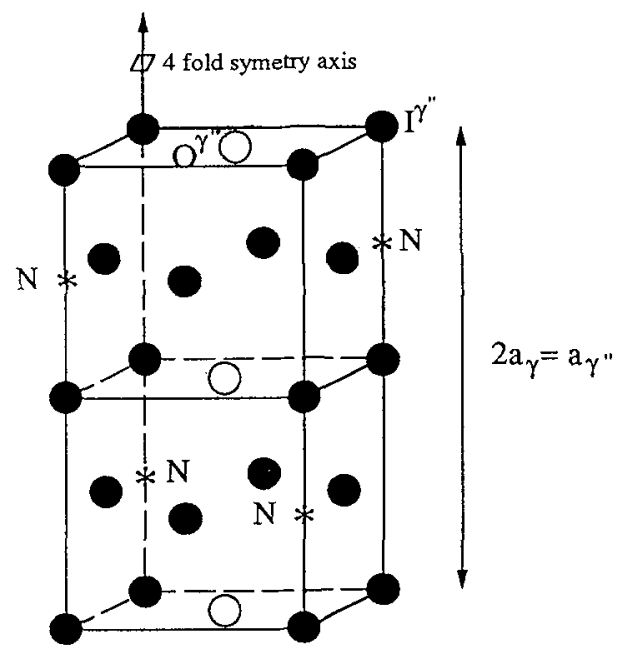

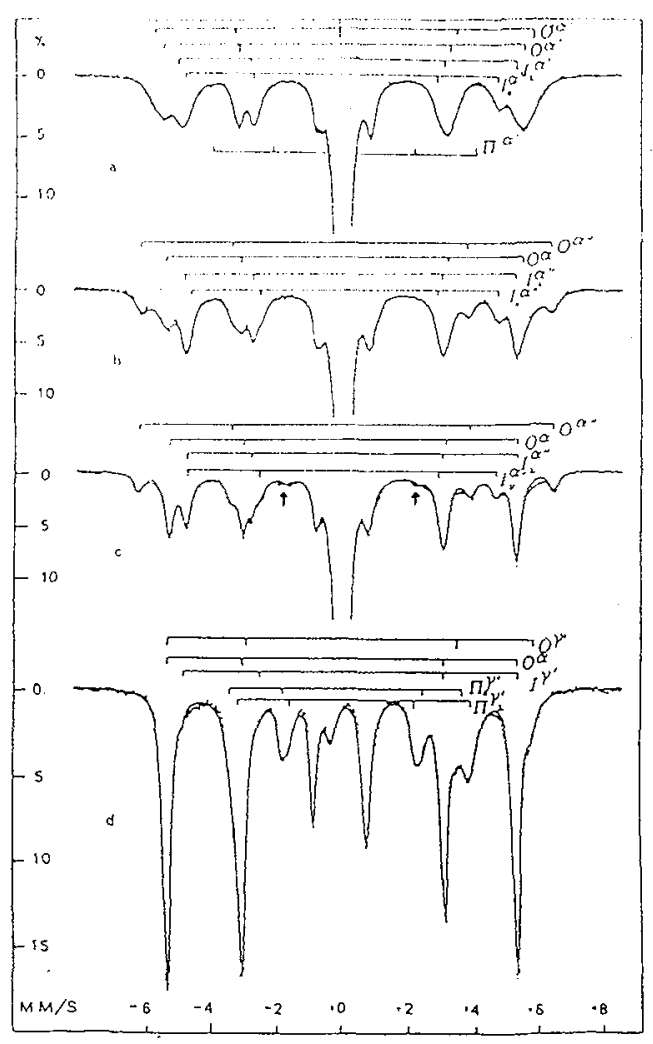

Figure 2: Mössbauer spectra at $293 \mathrm{~K}$ of a) virgin $\alpha^{\prime} \mathrm{FeN}_{0.1}$; after b) 3 secondes, c) 5 minutes and d) 13 hours ageing at $473 \mathrm{~K}$.

Figure 3: $\gamma^{\prime \prime}$ like structure.

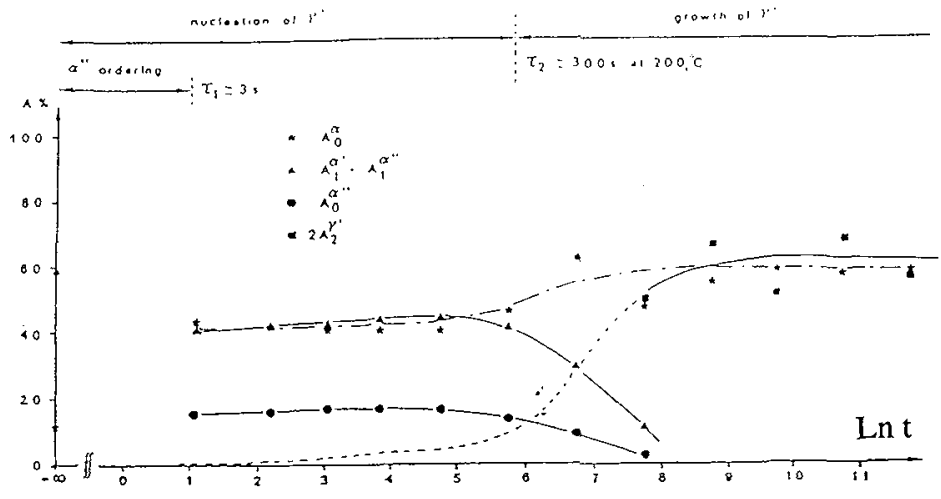

Figure 4: Variation of environment abundances $A_{i}^{\varphi}$ vs. Lnt during ageing of $\alpha^{\prime} \mathrm{FeN}_{0.1}$ martensite at $473 \mathrm{~K}$. First stage of ageing up to $\tau_{1}$ corresponds to $\alpha^{\prime \prime}$ ordering. Second stage corresponds to the formation of $\gamma^{\prime}$ nuclei arising from " $\mathrm{C}$ " clusters in $\alpha_{p}^{\prime}$ which ends as $\alpha$ ferrite. Third stage corresponds to the growth of $\gamma^{\prime}$ in $\alpha^{*}+\alpha$ as well as in $\gamma$ [18]. 